\title{
A educação a distância na perspectiva transdisciplinar: a contribuição das disciplinas de Laboratório de Pesquisa no curso de Pedagogia
}

\author{
Júlio José Cardoso Egreja - UCB (julioe@ ucb.br) \\ Michelle Jordão Machado - UCB (michellem@ucb.br) \\ Vânia de Aquino Silva - UCB (vaniaa@ucb.br)
}

\section{Resumo}

A educação a distância, por ser compreendida como uma abordagem que transcende os limites da dimensão espacial, temporal, cultural e curricular, apresenta-se intimamente associada aos princípios e características da transdisciplinaridade. A metodologia transdisciplinar está organizada em torno de três pilares, quais sejam: a complexidade, a lógica do terceiro incluído, e os diferentes níveis de realidade. Esta pesquisa visou analisar, à luz dessa teoria, as experiências desenvolvidas no conjunto de disciplinas Laboratório de Pesquisa no curso de Pedagogia, oferecido pela Universidade Católica de Brasília, na modalidade a distância. Os dados analisados foram coletados a partir de uma pesquisa realizada com estudantes do curso, em agosto de 2009. O processo de coleta deu-se por meio de um questionário enviado eletronicamente a 60 estudantes, matriculados do $2^{\circ}$ ao $6^{\circ}$ semestre do curso. A análise considerou os princípios da transdisciplinaridade, tendo como foco o conteúdo e as estratégias didáticas utilizadas na disciplina e a mediação pedagógica realizada pelo professor. Os resultados apontaram elevados índices de concordância dos alunos em relação às questões apresentadas, o que nos permite reconhecer nas disciplinas de Laboratório de Pesquisa os princípios dimensionados na teoria transdisciplinar.

Palavras-chave: educação a distância - transdisciplinaridade - laboratório de pesquisa

\begin{abstract}
Distance education, as an approach that transcends the limits of space, time, culture and curriculum, presents closely associated with the principles and characteristics of transdisciplinarity. The transdisciplinary methodology is organized around three pillars, that are: the complexity, the logic of the third included and the different levels of reality. This study aimed to analyze, through this theory, experiments carried out in all subjects of Laboratory Research of the course of Pedagogy offered by the Catholic University of Brasilia, in the distance mode. Data were collected from a survey conducted with the program students, in August 2009. The data collection process was done by a questionnaire sent electronically to 60 students enrolled from the 2nd to 6th semester of the course. The analysis considered the principles of transdisciplinarity, focusing on the content and teaching strategies of the subject and pedagogical mediation conducted by the teacher. The results showed high convergence rates of students on the proposed issues, which allows us to recognize the subjects of laboratory research on the principles of transdisciplinary theory.
\end{abstract}


Keywords: distance education - transdisciplinarity - laboratory research

\section{Introdução}

A realidade educacional atual, diante de um contexto complexo, plural e sujeito a emergências e imprevistos, é um dos grandes desafios dos profissionais da educação.

Nesse cenário, a educação a distância - EAD - tem se apresentado como uma modalidade renovadora, capaz de contribuir para a constituição de um novo paradigma educacional, permitindo a ampliação das relações interativas por meio das Tecnologias da Informação e da Comunicação - TIC - e a criação de condições de aprendizagem para uma educação colaborativa e cooperativa. Com práticas individuais e coletivas, e respeitando o ritmo de trabalho de cada um, a educação a distância apresenta-se intimamente associada aos princípios e características da transdisciplinaridade.

A transdisciplinaridade, por sua vez, é um princípio epistemológico que objetiva romper as fronteiras do conhecimento disciplinar, conduzindo a uma percepção para além dessas fronteiras. É a busca de um novo sentido da vida, voltado para o reconhecimento das relações entre os diversos saberes e as culturas presentes na sociedade.

Considerando, então, a perspectiva teórica da transdisciplinaridade, e tomando como principais referências Nicolescu (1999) e Moraes (2008), a pesquisa relatada neste trabalho visou analisar as experiências desenvolvidas no conjunto de disciplinas de Laboratório de Pesquisa no curso de Pedagogia oferecido pela Universidade Católica de Brasília, na modalidade a distância. A investigação buscou responder às seguintes questões: Quais são os pontos de convergência existentes entre a proposta das disciplinas de Laboratório de Pesquisa e os princípios da Transdisciplinaridade? Na percepção dos alunos, como ocorre essa aproximação entre a prática das disciplinas de Laboratório e os princípios de uma dinâmica transdisciplinar?

A pesquisa, de caráter quali-quantitativo, utilizou-se de dados coletados por meio de questionários enviados a estudantes do curso em agosto de 2009 , tendo como foco o conteúdo e as estratégias didáticas utilizadas nas disciplinas de Laboratório e a mediação pedagógica realizada pelos professores.

O desenvolvimento deste artigo contempla, inicialmente, as relações entre a educação a distância e a dinâmica transdisciplinar. Em seguida, apresenta uma breve explanação sobre o curso de Pedagogia oferecido na modalidade a distância pela Universidade Católica de Brasília, e esclarece, ainda, a proposta das disciplinas de Laboratório de Pesquisa do curso. Por fim, é apresentado o contexto da pesquisa, e são discutidos, à luz da perspectiva transdisciplinar, os resultados obtidos.

\section{Educação a distância: interfaces com a dinâmica transdiciplinar}

O século XXI descortina para a humanidade uma revolução sem precedentes históricos, consequência da globalização, impulsionada pelo avanço e desenvolvimento da tecnologia, e da revolução quântica, que redimensiona os princípios da lógica V. $7 \mathrm{~N}^{\circ}$ 3, dezembro, 2009 
clássica, quais sejam: determinismo causal, separatividade e a causalidade linear, bem como a insistência pela dimensão unidirecional. As fronteiras do mundo foram relativizadas. As informações passaram a ser disponibilizadas em rede, derrubando as barreiras de tempo e espaço. Neste contexto, a educação, um dos pilares significativos deste novo paradigma, também vem se amoldando à velocidade destas transformações, por meio, inclusive, da virtualização do processo educativo. Não há possibilidade de retorno, e não há como ficar indiferente às mudanças que se apresentam. Se a globalização, por um lado, possibilita a integração entre os povos, favorece intercâmbios, socializa informações, por outro tende a promover desigualdades sociais, discriminação, exclusão digital, comprometendo o futuro das próximas gerações e, porque não, da própria humanidade.

Nessa perspectiva, a realidade educacional que hoje se apresenta em um mundo repleto de incertezas, complexo, plural, indeterminado, sujeito às emergências e imprevistos, ainda é um desafio a ser enfrentado pelos profissionais da educação. Nesse cenário, a educação a distância se apresenta como uma modalidade enriquecedora, capaz de contribuir para a implementação de um novo paradigma educacional.

Esta modalidade compreende a troca, o diálogo e a interação professorestudante, estudante-estudante, professor-estudante-meio, privilegiando a autonomia do aluno que é estimulado a buscar, a investigar e a solucionar problemas que se apresentam, possibilitando seu completo envolvimento e compromisso com a produção do conhecimento. Assim, a EAD, segundo Moraes (2008, p.255),

possibilita o aumento do fluxo de informações, a interatividade, a ampliação e o rompimento das barreiras de tempo e espaço escolar, facilitando a ocorrência de interações multidimensionais e não bilaterais.

Cabe ressaltar que tais fundamentos e perspectivas para a EAD não estão relacionados ao uso tradicional da tecnologia, que tem por objetivo transmitir informações ao aluno e transpor, para as redes telemáticas, a virtualização da aula presencial, cuja comunicação normalmente tem sido empregada de forma bidirecional, entre professor e estudantes. Estamos, sim, retratando a tecnologia como a possibilidade do "estar junto virtual" (Prado e Valente, 2002), que "explora a potencialidade interativa da TIC, propiciada pela comunicação multidimensional que aproxima os professores, estudantes e contexto" (p.29), permitindo criar condições de aprendizagem por meio de uma educação colaborativa e cooperativa.

A educação a distância é compreendida como uma abordagem que transcende os limites da dimensão espacial, temporal, cultural e curricular, pois é concebida como sistema aberto, flexível, com práticas individuais e coletivas, mas principalmente, que respeita o ritmo de trabalho de cada um. Dessa forma, apresenta-se intimamente associada aos princípios e características da transdisciplinaridade.

A transdisciplinaridade é a busca do sentido da vida, de uma nova maneira de ser, de um novo modo de conhecer, de fazer e de conviver, por meio das relações entre os diversos saberes e as culturas da humanidade. Ela representa a possibilidade de articulação da objetividade e da subjetividade, da ordem e da desordem, do sujeito e do objeto, da razão e da emoção. Ultrapassa o campo das ciências exatas e, por meio do 
diálogo, permite reconciliação com a arte, a literatura, a poesia e a experiência anterior, conforme explicitado no art. $5^{\circ}$ da Carta da Transdisciplinaridade (Nicolescu, 1999). Não é uma nova ciência, nem uma nova religião, mas uma atitude ética que recusa etiquetagens, preconceitos, enfim, tudo que negue o diálogo e a discussão.

O conceito de transdisciplinaridade vem sendo construído ao longo dos anos, a partir de 1970, e em diversos encontros - França (1970), quando pela primeira vez o termo "transdisciplinaridade" é cunhado por Piaget; Veneza (1986), quando foi redigida a "Declaração de Veneza", com o intuito de incorporar o diálogo entre ciências exatas, humanas, artes e tradição; Paris (1991), onde surge a proposta da atitude transdisciplinar; Portugal (1994), onde foi escrita a "Carta da Transdisciplinaridade", dimensionando seus parâmetros, bem como seus princípios: múltiplos níveis de realidade, diferentes lógicas e complexidade; Suíça (1997), onde se debateu a evolução transdisciplinar na universidade e foi criada a Cátreda UNESCO para a difusão destes princípios; e Vila Velha (2005), com o objetivo de criar um espaço de discussão no que tange a pesquisa, reflexão, ação e atitude transdisciplinar.

A partir destes encontros e diálogos, surgiu em 1999 o Manifesto da Transdisciplinaridade, publicado por Basarab Nicolescu. No documento, podemos encontrar a sistematização da metodologia transdisciplinar a partir dos três pilares lançados no Congresso Internacional de Locarno/Suíça, que estão baseados nos princípios que norteiam a transculturalidade, a transreligiosidade e "transhumanismo", quais sejam: a complexidade, que deve ser entendida como um princípio articulador do pensamento e não como aquilo que é difícil e complicado de se compreender, como preconizado por Morin (1995); a lógica do terceiro incluído, que supera os binarismos entre o certo e errado para assim associar as categorias e conceitos aparentemente excludentes; e os diferentes níveis de realidade, que possibilitam a construção da noção da multimensionalidade e da multirrefencialidade do ser.

\section{O curso de Pedagogia na modalidade a distância: o caso da Universidade Católica de Brasília}

As Diretrizes Curriculares Nacionais afirmam a urgência e apontam os caminhos para o desenvolvimento dos processos formativos em Pedagogia, que devem ser baseados numa sólida formação teórica, prática, interdisciplinar e transdisciplinar. Tais processos deverão sustentar-se no trabalho coletivo, viabilizando compreender, em sua multidimensionalidade, a educação e a escola, cuja função social e formativa deve promover, com equidade, a educação para e na cidadania.

Neste sentido, a formação desejada no curso de Pedagogia da Universidade Católica de Brasília Virtual - UCB Virtual é a de um profissional com profundo conhecimento da dinâmica da sociedade e da educação, dos sistemas de ensino e da escola, enquanto realidades concretas de um contexto histórico-social permeados pelas dimensões afetiva e ética, individual e grupal.

Assim, a concepção curricular do curso de Pedagogia baseia-se numa visão integrada, complexa e transdisciplinar, superando uma concepção extensiva de currículo, que privilegia a transmissão de conteúdos, para um currículo intensivo, que V. $7 \mathrm{~N}^{\mathrm{o}} 3$, dezembro, 2009 
propõe a organização do trabalho pedagógico no enfoque trans e interdisciplinar e, na perspectiva de indissociabilidade entre ensino, pesquisa e extensão.

A partir da perspectiva anunciada, a estratégia de formação do curso de Pedagogia propõe a dinâmica de eixos temáticos, numa proposta diferenciada e inovadora: a complexidade e o conhecimento científico hoje; o contexto sócio-histórico da educação no Brasil e no mundo; o universo da aprendizagem; peculiaridades da educação infantil e ensino fundamental; "instrumentos metodológicos" que envolvem a práxis pedagógica (planejamento, registro, avaliação etc.) e as novas mídias e a educação - uma educação do presente com o olho no futuro.

Esses eixos são trabalhados ao longo do curso e, mas especificamente, nas disciplinas semestrais de Laboratório de Pesquisa presentes do primeiro ao último período do curso.

\section{Laboratório de Pesquisa: o que é, como se faz}

Dentre os desafios a serem assumidos nos cursos de formação de professores está o de transpor a cômoda e rotineira prática instrucionista, em busca de outras formas de atuação pedagógica que estimulem a criatividade e valorizem o espírito empreendedor, na busca de superação da transmissão de um conhecimento em forma de conteúdo pronto e elaborado.

Dessa forma, as disciplinas de Laboratório de Pesquisa visam articular-se às diversas disciplinas do semestre; trabalhar a pesquisa como princípio educativo, a partir dos problemas da educação nas diversas regiões do país e do mundo; desenvolver a produção acadêmica pelos estudantes e, por fim, proporcionar um estudo qualitativo utilizando-se das diversas mídias de educação.

Cabe ressaltar, ainda, que os Laboratórios de Pesquisa organizam-se em momentos de reflexão e análise do contexto local, nacional e internacional, a partir da elaboração pessoal de pesquisas; momentos de produção individual e coletiva e, por fim, momentos de socialização das atividades desenvolvidas. Nesse sentido, essa práxis se pauta no princípio estruturante da indissociabilidade entre ensino, pesquisa e extensão - e está comprometida com a construção da comunidade, por meio de testemunho solidário, do convívio fraterno e da co-responsabilidade.

A seguir são apresentadas de forma sintética as propostas das disciplinas de Laboratório de Pesquisa do curso de Pedagogia da UCB Virtual ${ }^{1}$.

Laboratório de Pesquisa I - focaliza a história de vida e a construção do sujeito educador, por meio da elaboração de um Memorial, que aborda a trajetória pessoal e profissional dos professores.

Laboratório de Pesquisa II - focaliza a constituição histórica da comunidade em que o estudante mora por meio da elaboração de um blog. Para tanto, ao longo do estudo são trabalhados os temas: a idéia do mito fundador, a constituição étnico-histórica da comunidade como elemento central para pensar a realidade educacional e a importância e o significado da pesquisa etnográfica e do estudo de caso para a pesquisa em educação. 
Laboratório de Pesquisa III - focaliza o reconhecimento do panorama da Educação Básica Brasileira a partir de dados comparativos sobre a realidade contemporânea. Para tanto é realizada uma pesquisa bibliográfica e desenvolvida, ainda, a projeção de cenários a partir de dados e séries históricas sobre a realidade atual da educação brasileira. A pesquisa é, ainda, socializada por meio da utilização da ferramenta webquest.

Laboratório de Pesquisa IV - focaliza a situação da Educação em dimensão Internacional e visa contribuir para a formação do professor-pesquisador com base no estudo de caso, como tipo de pesquisa, bem como no questionário, na entrevista e na análise documental, como instrumentos que podem auxiliar pesquisas educacionais qualitativas.

Laboratório de Pesquisa V- focaliza a vivência da pesquisa participante. Neste modelo de investigação, o pesquisador integra-se ao contexto investigado e convive por certo tempo com os sujeitos de pesquisa. A disciplina aborda a dimensão das dificuldades de aprendizagem e é sistematizada ou por meio da ferramenta de audioconferência ou por meio de um programa de rádio.

\section{Desvendando práticas transdisciplinares no ambiente virtual}

\subsection{O contexto da pesquisa}

Esta pesquisa visou analisar, à luz da perspectiva transdisciplinar, as experiências desenvolvidas no conjunto de disciplinas de Laboratório de Pesquisa no curso de Pedagogia oferecido pela Universidade Católica de Brasília, na modalidade a distância.

Os dados analisados nesse trabalho foram coletados a partir de uma pesquisa realizada com estudantes do curso, em agosto de 2009. O processo de coleta dos dados deu-se por meio de um questionário enviado eletronicamente a 60 estudantes, matriculados do $2^{\circ}$ ao $6^{\circ}$ semestre do curso.

O questionário foi elaborado considerando-se, em linhas gerais, os princípios da transdiciplinaridade e tendo como foco o conteúdo e as estratégias didáticas utilizadas na disciplina e a mediação pedagógica realizada pelo professor. Cabe ressaltar, porém, que a tríade transdisciplinar - complexidade, lógica do terceiro incluído e diferentes níveis de realidade -, mesmo apresentando características específicas que definem cada um de seus eixos, também apresenta pontos fortemente imbricados, o que dificulta a elaboração de questões que possam ser caracterizadas como pertencentes a um único eixo.

Organizado em 8 questões, o instrumento objetivou verificar a avaliação dos alunos sobre as disciplinas de Laboratório de Pesquisa, observando o grau de concordância de cada um em relação às questões apresentadas. Além disso, o instrumento contemplou ainda uma etapa discursiva, de modo que o estudante pudesse registrar justificativas para a opção selecionada. Portanto, o instrumento de coleta propiciou a análise quali-quantitativa, a partir da relação entre os dados estatísticos e os comentários dos estudantes. 
Vinte e cinco estudantes devolveram os questionários com as respostas que nortearam a discussão. Esses 25 alunos correspondem a $20 \%$ do universo de estudantes que haviam concluído pelo menos uma disciplina de Laboratório de Pesquisa no curso.

A orientação aos respondentes foi a de que avaliassem a disciplina de Laboratório de Pesquisa que haviam cursado no semestre anterior. Cada disciplina de Laboratório de Pesquisa (I, II, III, IV e V) foi avaliada por cinco estudantes, perfazendo o total dos 25 respondentes. Cabe ressaltar que, apesar da separação das disciplinas no processo de coleta dos dados, a pesquisa realizada não teve o objetivo de analisá-las separadamente, mas sim no seu conjunto.

\subsection{Discussão dos resultados}

Os resultados da aplicação dos questionários foram tabulados por questão e são apresentados na Tabela 1. Considerando que os enunciados de todas as questões abordam qualidades de uma prática transdisciplinar, optou-se pelo tratamento conjunto dos resultados, expresso pela média geral, o que fornece uma visão panorâmica da percepção do aluno acerca das disciplinas de Laboratório de Pesquisa.

Tabela 1 - Nível de concordância dos estudantes em relação às questões apresentadas

\begin{tabular}{l|c|c|c|c}
\hline \multicolumn{1}{c|}{ QUESTÃo } & \multicolumn{2}{c}{ NÍVEL DE CONCORDÂNCIA (PERCENTUL) } \\
\cline { 2 - 5 } & $\begin{array}{l}\text { Concordo } \\
\text { plenamente }\end{array}$ & $\begin{array}{l}\text { Concordo/ } \\
\text { discordo } \\
\text { parcialmente }\end{array}$ & $\begin{array}{l}\text { Discordo } \\
\text { totalmente }\end{array}$ & $\begin{array}{l}\text { Não tenho } \\
\text { opinião }\end{array}$ \\
\hline $\begin{array}{l}\text { 1. As estratégias utilizadas no Laboratório de Pesquisa } \\
\text { contribuíram com a possibilidade de contato com diferentes } \\
\text { contextos e realidades culturais. }\end{array}$ & 88 & 8 & 4 & 0 \\
\hline $\begin{array}{l}\text { 2. O conteúdo do Laboratório de Pesquisa auxiliou-me a } \\
\text { compreender fenômenos sob óticas diversas. }\end{array}$ & 84 & 16 & 0 & 0 \\
\hline $\begin{array}{l}\text { 3. O Laboratório de Pesquisa propiciou-me a abertura para } \\
\text { a aceitação do desconhecido, do inesperado do imprevisível. }\end{array}$ & 80 & 16 & 0 & 4 \\
\hline $\begin{array}{l}\text { 4. As atividades propostas motivaram-me a associar as } \\
\text { teorias estudadas a questões práticas do meu cotidiano. }\end{array}$ & 80 & 12 & 8 & 0 \\
\hline $\begin{array}{l}\text { 5. O Laboratório de Pesquisa ajudou-me a cultivar o rigor } \\
\text { na argumentação. }\end{array}$ & 84 & 16 & 0 & 0 \\
\hline $\begin{array}{l}\text { 6. A atuação do/a professor/a do Laboratório de Pesquisa } \\
\text { propiciou a integração entre aspectos cognitivos e afetivos. }\end{array}$ & 80 & 16 & 0 & 4 \\
\hline $\begin{array}{l}\text { 7. As atividades propostas incentivaram-me a desenvolver o } \\
\text { senso crítico. }\end{array}$ & 84 & 16 & 0 & 0 \\
\hline $\begin{array}{l}\text { 8. A metodologia de pesquisa proposta incentivou-me à } \\
\text { prática da sensibilidade e da criatividade. }\end{array}$ & 88 & 12 & 0 & 0 \\
\hline \begin{tabular}{l} 
DEÉDIA \\
\hline
\end{tabular} & $\mathbf{8 3 . 5}$ & $\mathbf{1 4}$ & $\mathbf{1 . 5}$ & $\mathbf{1}$ \\
\hline
\end{tabular}

Esses resultados quantitativos apontam elevados índices de concordância dos alunos em relação às questões apresentadas, o que nos permite reconhecer nas disciplinas de Laboratório de Pesquisa os princípios da transdisciplinaridade presentes na literatura.

As estratégias didáticas adotadas, por si só, já constituem um importante indicador para sustentar essa afirmação, pois elas conduzem o estudante à observação V. $7 \mathrm{~N}^{\mathrm{o}} 3$, dezembro, 2009 
da diversidade, como possibilidade de aceitação das diferenças e das contradições. Uma atitude transdisciplinar reconhece o outro como legítimo outro, numa dimensão de alteridade que busca o constante exercício da lógica do terceiro incluído, bem como os diferentes níveis de realidade.

As disciplinas propõem um novo modo de encarar o conhecimento, de forma integrada aos contextos, aos sentidos produzidos pelos sujeitos, interligando áreas diferentes no desenvolvimento de significados. Não apenas a proposta inicial da disciplina ou os dados quantitativos revelam essa perspectiva, mas também os depoimentos apresentados pelos estudantes, como se vê a seguir e ao longo de toda a discussão dos resultados:

A disciplina me ajudou a "encarar" a educação de uma forma diferente. Veio para reforçar que os seres humanos são distintos quanto as suas capacidades mentais e motoras. Cada ser humano tem a sua própria percepção de realidade e reage ao mesmo estímulo dado de maneiras diferentes. (E1)

Outro fator importante a ser considerado diz respeito à mediação pedagógica. Para Moraes (2008, p.159),

a mediação pedagógica, sob o olhar da complexidade, valoriza não só a presença enriquecedora do outro, mas também a humildade e a abertura ao reconhecer a presença das múltiplas realidades, a provisoriedade do conhecimento e a presença do aleatório em nossas vidas.

Nos Laboratórios de Pesquisa, observa-se que essa mediação considera a abertura para o diálogo e a possibilidade de construção de múltiplas visões em torno de um mesmo fenômeno. A prática transdisciplinar envolve processos culturais, sociais, afetivos e interativos e, por isso, exige uma ação docente aberta ao diálogo, de forma sensível, cooperativa e ética, respeitando as diferenças, possibilitando a construção de saberes conectados com os indivíduos e com o todo, e permitindo a transformação do eu e do outro.

Nos fóruns tínhamos espaço para apresentar nossas idéias e também de conhecer as idéias dos nossos colegas, sempre de maneira cordial e respeitosa. (E2)

A professora nos deixou à vontade para expormos as nossas convicções sobre os assuntos abordados. (E3)

A esse respeito, Moraes (2008, p. 249) esclarece, ainda, que

a interação é condição necessária para a construção do conhecimento, enfim, é a dimensão deste paradigma. O sujeito age sobre o objeto e, ao mesmo tempo, em função do acoplamento estrutural que acontece entre ambos, ele sofre ação do objeto e assim sua capacidade de conhecimento se desenvolve enquanto produz conhecimento. 
$\mathrm{Na}$ perspectiva do pensamento complexo, a aprendizagem é resultado da relação entre indivíduo e meio, por isso a mediação pedagógica deve incentivar a livre expressão, a criatividade e propiciar condições para o crescimento cognitivo, existencial e emocional dos estudantes.

As disciplinas ajudaram na construção dos meus pensamentos, na construção das minhas argumentações, contribuíram significativamente para um crescimento pessoal, acrescentando muito no meu aprendizado. E o feedback dos tutores, mais ainda. Auxiliaram na organização e a sistematização dos conhecimentos e foram eficazes para ampliá-los, articulando e sistematizando os conhecimentos repassados pelo conteúdo das matérias, tratados nos fóruns e obtidos através de pesquisas em livros, filmes e na internet. (E2)

A proposta de trabalho dos Laboratórios, uma vez organizada em torno de estratégias didáticas de pesquisa, favorece uma visão dinâmica dos fenômenos estudados, por meio do diálogo entre teoria e prática, e transfere para o estudante o controle do seu aprendizado, incentivando a autonomia intelectual e o aprendizado através de práticas significativas.

As atividades propostas possibilitaram um desenvolvimento do meu raciocínio e auxiliaram na elaboração das minhas participações nos fóruns das diversas disciplinas. Portanto, acredito que tenham ajudado a desenvolver o meu senso crítico. (E3)

Nessa linha de entendimento, a pesquisa, como recurso para aprender a conhecer a partir da aproximação com os problemas da profissão e da sociedade, constitui-se uma estratégia importante do "ensino com ciência", que poderá possibilitar o desenvolvimento das aptidões necessárias à aproximação entre o conhecimento existente e o desconhecido, na perspectiva de novas e significativas elaborações para que o estudante esteja capacitado para reinventar processos e soluções necessários a um mundo em permanente mudança.

Venho aplicando diariamente os conteúdos e os pontos aprendidos ao longo dos semestres nas disciplinas de Laboratório, aplicando-as também em minha vida e em outras disciplinas. Esse aprendizado vem possibilitando a sistematização dos meus pensamentos, minhas idéias, aprendizagens e dúvidas, de modo a avaliar meu processo de aprendizagem. Foi possível observar minhas construções e criações que foram se desenvolvendo ao longo dos meus estudos. (E4)

Segundo Moraes (2008), ao se inquietar, ao dialogar e ao buscar explicações para suas dúvidas, o estudante encontrará respostas, mas também outras dúvidas, que o impulsionarão a continuar buscando novas respostas, fazendo-o entrar num processo contínuo de construção do conhecimento.

Tivemos muitas atividades individuais, que nos levaram ao exercício constante do pensamento complexo, do desenvolvimento da escrita e do raciocínio e ao mesmo tempo alguns trabalhos em grupo. A

V. $7 \mathrm{~N}^{\mathrm{o}} 3$, dezembro, 2009 
simples participação nos fóruns de discussão são atividades diárias de interações com os colegas que nos fazem crescer muito. (E5)

Dessa forma, o estudante passa a ser protagonista de espaços desafiadores, inovadores e, ao mesmo tempo, aconchegantes, pelo diálogo de experiências, de debates, de perguntas e de resoluções de problemas, organizados pelo mediador do processo educativo - o professor. As justificativas apresentadas pelos estudantes apontam justamente nessa direção:

$\mathrm{O}$ inesperado e o desconhecido nos assustam e nos causam certas limitações. Fomos assistidos de forma espetacular, o que fez com que a disciplina apesar de um pouco difícil se tornasse prazerosa. (E6)

Por fim, no que diz respeito aos conteúdos disciplinares, a prática dos Laboratórios de Pesquisa tem incentivado a construção de uma consciência em relação aos fenômenos da vida. Uma vez estruturado por temas, os conteúdos focalizam a importância do contexto, das emergências individuais e coletivas, sociais e culturais e, principalmente, conduzem à compreensão de que esses aspectos não estão separados do sujeito, mas fazem parte dele.

Sempre vivenciei um mundo diferente do que sempre li e os trabalhos com Laboratório me deram a oportunidade de aprofundar e participar desses assuntos que até antes existiam, mas fora da minha realidade. (E7)

\section{Considerações finais}

O processo de formação não pode ser diminuído em sua dimensão educativa, reduzindo-se a um processo de instrução. Este último pode se contentar com a aquisição de saberes - dimensão que remete ao domínio teórico de conceitos - ou de saber fazer dimensão que remete ao domínio das diferentes metodologias e técnicas. Uma formação autêntica requer também o desenvolvimento da capacidade de saber ser, de saber ou de poder tornar-se. Da mesma forma que deve visar a desenvolver nas pessoas, grupos e organizações a capacidade de saber situar-se social e historicamente.

A natureza do conjunto de disciplinas de Laboratório de Pesquisa tem viabilizado a relação entre as dimensões histórica, política, social e cultural em que estamos inseridos. Dessas dimensões emerge o entendimento de que o ensino é práxis social, resultante das interações que constituem a construção do conhecimento, no sentido de permitir aos sujeitos envolvidos no processo refletirem sobre a própria cultura e os contextos sociais a que pertencem, (re)inventando, constantemente, uma prática social educativa capaz de gerar uma pedagogia viva, cidadã e participativa.

Nesse processo, as tecnologias midiáticas têm proporcionado a "abertura das grades, até então fechadas", oferecendo novos espaços de conhecimentos e contribuindo para o deslocamento do eixo de ensino para o eixo da aprendizagem. Agora que estamos definitivamente conectados à nova era, de um mundo enredado, ou seja, interdependente, novas competências e habilidades deverão ser desenvolvidas para que possamos continuar aprendendo ao longo da vida, inclusive aprendendo a V. $7 \mathrm{~N}^{\circ}$ 3, dezembro, 2009 
viver/conviver com as diferenças, compreendendo as diversidades e as adversidades, reconhecendo a pluralidade e multidimensionalidade da realidade (Moraes, 2008).

Para finalizar, podemos afirmar que a interação entre a educação a distância e a transdisciplinaridade possibilita pensar no desenvolvimento de uma aprendizagem construída por princípios intuitivos, imaginários, cooperativos, incluindo o resgate do amor, prazer, respeito nas relações, mas, principalmente, da idéia de consideração da vida. O processo educativo, por meio da atitude transdisciplinar, poderá ir além das disciplinas por estar entre e através dela. $\mathrm{O}$ rigor na argumentação, a abertura ao desconhecido e a tolerância às diferenças farão parte dessa verticalização em que o ser humano poderá retomar os aspectos qualitativos do conhecimento.

\section{Notas:}

${ }^{1}$ Até o momento da coleta de dados o curso de pedagogia encontrava-se no $6^{\circ}$ período letivo e, portanto, as propostas apresentadas são atividades desenvolvidas do $1^{\circ}$ ao $5^{\mathrm{a}}$ semestres do curso.

${ }^{2} \mathrm{Na}$ seleção das justificativas apresentadas pelos estudantes, buscou-se não repetir depoimentos de um mesmo aluno e foram consideradas as diferentes questões propostas, bem como os diferentes semestres sob análise, de forma a compor uma amostra o mais abrangente possível para evidenciar a opinião do grupo sobre conjunto de disciplinas.

\section{Referências Bibliográficas}

PRADO, M. E. B.; VALENTE, J. A. A Educação a Distância possibilitando a formação do professor com base no ciclo da prática pedagógica. In: MORAES, M. C. Educação a distância: fundamentos e práticas. Campinas: OEA/MEC, Unicamp: NIED, 2002.

MORIN, Edgar. Introdução ao pensamento complexo. Lisboa: Instituto Piaget, 1995.

MORAES, Maria Cândida. Pensamento eco-sistêmico: educação, aprendizagem e cidadania no século XXI. $2^{a}$ edição. Petrópolis: Vozes, 2008.

MORAES, Maria Cândida; VALENTE, José Armando. Como pesquisar em educação a partir da complexidade e da transdisciplinaridade? São Paulo: Paulus, 2008.

NICOLESCU, Basarab. O manifesto da transdisciplinaridade. São Paulo: Triom, 1999. 